\title{
Geneva School and Its Critical Theory
}

\author{
*Song Aimeng \\ Theory of Literature and Art, Yanbian University, Ji Lin, China \\ jxkdhssam@163.com

\begin{abstract}
The "Geneva School" in this article refers to the history of literary criticism. It began to rise in the 1960s and 1970s, and then spread to Europe. It was once prosperous. The group represented by George Bligh has some kind of relationship with Geneva. A school of literary criticism composed of relational critics. The main members of the "Geneva School" include: George Bly, Jean Starobinski, Jean-Pierre Richard and Jean Luce. Although their research methods have their own characteristics, they maintain a consistent view of the aesthetic interpretation of the text, that is, a sense of criticism. In this article, the author further studies and interprets the Geneva School and its critical theory by tracing the origin of the Geneva School theory.
\end{abstract}

Keywords: Theoretical Tracing, Geneva School, George Bly

\section{INTRODUCTION}

The "Geneva School" is guided by the theory of "critical consciousness" and participates in the aesthetic practice of literary and artistic works. Under the theoretical background of phenomenology and other theoretical backgrounds, critics of the Geneva School explained the core of aesthetic interpretation, which is to free up self-participation in the creator's self-thinking, and finally reach the process of identification.

\section{FOUNDATION LAYING: PHENOMENOLOGY}

Under the foundation of phenomenology, the object of literary research was clarified, and consciousness was regarded as the main object of literary criticism and research by George Bly. The theory of "critical consciousness" of the Geneva School put forward literature and artistic works as a form of expression, which concentrated on In order to understand human consciousness, literary criticism achieves a kind of "essential intuition" through the "phenomenological restoration" of this kind of human consciousness, and obtains the restored "pure consciousness" in this kind of consciousness criticism.

Phenomenology specializes in the study of pure consciousness, and its purpose is to describe the activity and essence of pure consciousness. As a philosophical school, it has experienced the inheritance and development of Husserl, Merleau Ponti, Sartre, and other philosophers since its inception. Based on the theory created by Husserl, Merleau Ponti successfully brought phenomenology out of the field of philosophy and applied it to a wide range of other fields, causing a wave of phenomenology in the entire French cultural and artistic field. In the theories and methods of phenomenology, the aspects of "suspension", "reduction", "intentionality" and "intersubjectivity" have exerted extensive and far-reaching influence on the development of literature and aesthetics in the 20th century. It can be said that the penetration of phenomenological philosophy in various fields is giving the Geneva School a real thickness and foundation in critical theory. Without phenomenological theory, such a school would not have emerged. The "essential intuition" and "pure consciousness" theories put forward by the philosophy of phenomenology have ignited the light of exploration and criticism of the Geneva school: if there is no method of phenomenology philosophy, the aesthetic interpretation of the Geneva school will not be activated, and all aesthetics His extravagant hopes or bold ideas can only be locked in a castle in the air, and become empty talks that cannot be realized.

Influenced by Husserl' $\mathrm{s}$ phenomenology, the Geneva School found the cornerstone of its methodology. The fundamental method of phenomenology is to directly and intuitively grasp the 
unchanging essence in various real contents and changing intentional contents, as long as consciousness Existence, this essential law is universally effective. This provided a phenomenological research method for the theory of "critical consciousness", and the Geneva School flexibly mastered the theory of "reduction of phenomenon" and "reduction of essence" in Husserl's phenomenology, absorbing its essence and integrating it into its own unique Critical methodology. It can be said that Husserl' s phenomenology has made "critical consciousness" a critical school and a trend of critical thought, laying a solid theoretical foundation for the Geneva School and providing a series of solid and scientific critical methods. Er's phenomenology, all the desires of the Geneva School of aesthetic interpretation are empty talk. Inspired by Husserl's phenomenological philosophy and methods, George Bly established the main theoretical methods of literary criticism and research, taking consciousness as the main goal of research. He advocates that literary works should be expressed through human consciousness, and literary criticism is to "phenomenologically restore" human consciousness to achieve a kind of "essential intuition", and obtain a kind of "pure consciousness" through this method of reduction. . George Bly believes that in the process of literary criticism, the subject and the object of criticism are an inseparable unit, and the subject and the object must communicate with each other, merge into one, and coexist. Literary and artistic works are not simply objects composed of words using techniques, but the product of the interaction between the subject's mind and will. Therefore, the author's conscious activity is the activity of literary works.

\section{GEORGE BLY AND "CRITICAL CONSCIOUSNESS"}

The specific criticism strategy of the Geneva School is mysterious, so it can only produce some insightful critical results less assuredly. These results are not because of their critical consciousness and become insights, but more because of the critics. Vision and ability. The Geneva School's understanding of the consciousness of readers is also self-contradictory. The consciousness of readers is not only a slave to let another subject's consciousness gallop, but also a subject with its own creative behavior. The critics have already sensed their own self-consciousness, but they want to It is ridiculous to use mysterious phenomenology to restore pretending that oneself does not have the freedom to be a subject, which is ridiculous, and it further hurts the guiding significance of the Geneva school theory to critical practice.

George Bly also noticed that his theory lacks practicality and that the freedom of critics needs to be recognized. Therefore, he also proposed a set of more specific criticism strategies in order to try to solve his own ideological problems. Bligh examines the degree of critics' identification with works in history, in order to find an appropriate way of criticism. He believes that there are two extremes in the relationship between critics and works. One is complete sensibility and thorough devotion. Critics must reproduce the sensuous world of works through their own language. Criticism becomes a kind of literary creation, and the other is a kind of literary creation. Reasonably alienate, and interpret the work through an abstract sense of independence. Realistic criticism always oscillates between two possibilities. Bly uses his own theory to try to reconcile these two different methods, thinking that these two methods are the performance of the process from the subject to the subject through the object. The way to balance the two is to go through the three stages of criticizing the subject's own consciousness. In the first stage, the subject must be fully perceptually integrated into the object, and the second stage must go beyond the formal object and experience the meaning in words, and the third stage It focuses on this meaning, because this meaning has no object or any structure that can express it. It is an idea, a pure consciousness, and to obtain this consciousness must rely on essential intuition.

George Bly's "Critical Consciousness" is a landmark work of the Geneva School. It summarizes the literary criticism methods and principles of the critics of the Geneva School in Bly's book. Therefore, the so-called "critical consciousness" theory, Is a name for the generalization of the theory of the critics of the Geneva School. Through the summary of George Bly, it can be found that Bly has selected the words "I think", "identity", and "intentionality" to summarize and integrate the book "Critical Consciousness".

In the book "Critical Consciousness", George Bly revealed the different ways in which critics of the Geneva School searched for the target of criticism "I think", and theoretically clarified various concepts of critical consciousness, and its main purpose It is to show how to run the "I think" process and the method used to capture the "I think". George Bly believes that discovering "I think" is the primary task of critics in literary criticism. The key to measuring the success of a critical behavior is that critics can successfully approach and "rediscover" the author's "I think". George Bly has re-understood "I think". In his view, the real "I think" reveals the mystical relationship between me and the world. The subject is aware of himself while also perceiving how much he has. In the world. Therefore, the subject is not purely logical "I think", but an existence belonging to the world. "I think" is the starting point of speculation and the "initial moment" of consciousness. Therefore, works start from here, and criticism with works as research objects should also start from here. He believes that "I think" is not only the awareness of the self, but also the knowledge of the 
environment in which the self is located. The two are inseparable. The author's self and the reader's self are merged into one in the work. Regarding how critics can "discover" the writer's self-thinking in literary criticism, George Bly believes that "'me-thinking' is an act of intelligence perceived from the inside." When appreciating literary and artistic works, It is necessary to interpret the writer's mind, understand the mind of oneself, and also to understand the world. This activity of reading and appraisal is the mission respected by the critics of the Geneva School, that is, the "mission of criticism."

Literary criticism is fundamentally a criticism of "consciousness", that is, the writer's "I think", and reading is a medium used to awaken the consciousness of criticism. Through reading works, the subject of criticism and the subject of creation generate an identity. The so-called "identity" refers to a kind of chasing and sympathy between the writer's "me thinking" and the critic's "me thinking", that is to say, the consciousness of the writer and the consciousness of the reader must be integrated and unified. That is, the fusion and unity of the creation subject consciousness and the criticism subject consciousness. In George Bly's view of identity, the critics have not completely lost themselves, and the critics still continue their own conscious activities. Therefore, the identity relationship emphasized by George Bly is a kind of the critic's awareness of the creator. Identity, what Bligh advocates is a kind of identity between the subject and the subject. He believes that critics use works as a medium to understand the intentions of creators, and creators use works as a medium to present their emotions and thoughts. Therefore, the consciousness of critics and creators can be achieved through literary and artistic works. Perfect fusion. "Critical consciousness" theory believes that when reading activities, readers need to use the memories and impressions that exist in the deep layer of their brains to perceive the same or similar feelings and impressions as the writer from themselves, so that readers can achieve communication with the writer's life Similar. The status between the subject of criticism and the subject of creation is equal and agreeable. George Bly called "identity" in "Critical Consciousness" as "intersubjective equivalence". He believes that in a work, the entire and true relationship between the author and the critic is a kind of intersubjective relationship. Phenomenon, so the communication relationship between the author and the critic is an equivalent "I think". The theory of "critical consciousness" believes that literary criticism is a kind of creative writing, a language activity related to the main body of critics, and critics express their thoughts and character through critical writing.

Critics of the Geneva School believe that the main work of literary criticism is to reveal the intentionality of a work. Intentionality is the product of the interpenetration of multiple modes used by the writer and the objective world. Only in the activities of internal analysis of the text, literary criticism The rich and varied intentionality in the art works can be exposed. George Bly believes that literary and artistic works are an "intentional" object full of author consciousness. Reading is to reproduce the author consciousness in the work in the minds of readers. That is to say, literary and artistic works are an intentional object. The sexual object, in the language structure of this object, leaves the mark of the writer's consciousness. Therefore, the main work of literary consciousness criticism is to reveal the intentional structure of literary and artistic works, because only through criticism can the writer's unique consciousness imprinted in literary and artistic works be found.

\section{OTHER KEY MEMBERS}

Critics of the Geneva School have maintained a consensus on reading activities and criticism activities, that is, they all believe that literature and art are a phenomenon of human consciousness, and literary criticism is fundamentally a criticism of this consciousness, a kind of consciousness. The activity is about the consciousness of consciousness. However, in terms of theories, viewpoints, and critical methods, the critics of the Geneva School are different. In some respects, they even show great differences. Their criticism styles can be said to have their own characteristics and their criticism methods are diversified. , Each "maintain the spirit of independence." Describe the other four representative figures mentioned in the book:

The identification criticism proposed by Marcel Lemmon emphasizes that there must be an identification relationship between the critic subject and the critic object. Before this identification is achieved, there must first be a kind of "ascetic" to break away the barriers of self, that is, critics. When recognizing a poem or a piece of art, one must abandon his foresight, abandon the mentality of doubt, resistance, criticism, etc., and get rid of all the society, history, politics, culture, etc. that are irrelevant to the original pure self, so that you can enter A state of pure acceptance. Next, Marcel Lemmon proposed to adopt an experience method to enter the work, and to directly enter the work in a way of participation and identification. He believes that entering the work can directly experience poetry without any intermediary. Not a poet, he refuses to meet the poet, refuse their conversation, because the poet has put everything into the work. That is to say, the identity criticism emphasized by Marcel Leman is to criticize the subject's identity with the work, which is a fusion of subject and object. He was influenced by Rousseau on this point, and Rousseau expressed similar thoughts in "Walking Reverie". The subject plunges into the 
objective nature in a state of almost selflessness. There is neither happiness nor sorrow in the heart, neither fear nor enjoyment. Under the subject's care, the beauty of nature has a panoramic view, achieving a kind of The situation where the subject and the object blend into each other. However, Marcel Lemmon believes that this kind of object is an object that contains all the energy of the creative subject, that is, an object with the creator's subjective consciousness.

Jean Starobinski attaches great importance to critical methods. He believes that literary criticism is an eye with a living soul. Therefore, he advocates that literary criticism is a kind of "gaze" and created a unique "gaze" in the history of literary criticism. aesthetics". The "gaze" emphasized by Jean Starobinski is actually a kind of reading. Critics face literary works and criticize in the course of reading. This is a combination of passive and active. When passive, it is " "Answer", "Inquiry" when active. That is to say, the nature of the objective existence of a literary work determines that when reading a work, one has to accept the thoughts imposed on others by the work. At this time, people passively "respond"; and as a reader, they "gaze" while reading. In order to maintain a right to the gaze of the reader, reading must start with the "gaze" of what is initially presented in front of the eyes, and continue to move forward until it encounters the deeper meaning of the literary work. At this time, it is an active "inquiry". ". This "gaze" of Jean Starobinski attaches great importance to the grasp of the relationship between the subjects. The premise of the "gaze" is the constant collision between the critic subject and the critic subject to produce new meaning. Criticizing subjects continue to adopt a "gaze" approach to themselves and the world, and to examine the gap between the criticized object and themselves. Consciousness is not a thing of existence, but just a kind of "gaze." Its understanding of existence is pure and external, and it can even be said to be somewhat remote and infinite. Literary criticism can fill up all the objectification gaps. Therefore, criticism has become the window to the human soul and the spiritual eye. Through the gaze of literary works, it can clearly show the world scene and life scene of the work. Through the role of "gaze", criticize the subject's transcendence of all forms of factors, thereby understanding the consciousness of the creative subject.

Another famous figure of the Geneva School, Jean Luce, whose main work is "Form and Meaning" (1962). In "Form and Meaning", Jean Luce believes that the relationship between "mode and language" is very important, and the writer's emotions should be linked to their form. The model of style is based on the unity of words and thoughts. If selected properly, the inner cohesive emotional center of the author will be revealed, and all the details have the same importance in the relationship with the whole. Style and soul are the two essential premises of the work, and they are also two aspects of the same internal phenomenon that are essentially separated from man. In other words, the artist has no external style, he is his style. He can only carefully exclude things unique to one of his phenomena, and achieve a universal "essential intuition." Luce devoted himself to the description of the system experience model in order to seek the universal essence from it. He wants to discover a total system in the experience mode of "form and meaning", that is, through his own criticism to penetrate the recurring form, structure, and interpretation modes in all the author's works, thereby approaching the essence of the work. In phenomenological thinking, the work is the origin of meaning, not its end. It is constantly being created again and again in the process of its own creation, reshaping its own future in criticism. The key reason why the work is always new and evergreen lies in the critical spirit of writers, readers and critics. Only with a new spirit can the form and structure of death be regenerated, and a unique spiritual life can be obtained. In this sense, criticism is a deduction of self-consciousness. It acquires a kind of spirituality as the work takes shape, and it continuously spreads in the interpretation of the work-conscious criticism and work consciousness become a perfect whole.

Jean-Pierre Richard, born in 1922, his main works include "Literature and Sensation" (1954), "Poetry and Depth" (1958), "The Imaginary World of Mallarmé" (1961), " About Poetry Studies (1964). In Jean-Pierre Richard's view, phenomenological criticism is the integration in the literary structure. This integration is essential, and its essential manifestation is diametrically opposed to the new criticism. New criticism always seeks to cut off the involvement of the author's emotions and accept the involvement of criticism emotions. The Geneva School believes that intentionality is the mutual intervention of multiple modes between the author and the world. It can only be achieved through the internal analysis of the text. It is possible to reveal the rich and varied intentionality in the work. In terms of the ontology of works, Richard emphasizes that the structure of works is the primary work of critics. He pays attention to analyzing the linguistic organization and imaginary composition of works from the perspective of structure, and uses poetic language descriptions to remind people of a kind of organism. The work is embodied as a complete totality of intentional objects. Therefore, he strives to express the feelings and emotions of the way to the world through language, and when analyzing the objects, he fully stimulates the emotions of the critics, that is, through the external world and the world of works to detect the problem of intentionality. Revealing the intentionality of the work has become the main work of Richard. Richard believes that aesthetic interpretation cannot be satisfied with thinking about a kind of thought, and it should be traced back to "feeling" image by image through this thought. 
Aesthetic interpretation must not only grasp the subject and self, but also grasp the object and matter. While noting the author's consciousness, critics are also reconstructing and extending this work. When a round of aesthetic interpretation is completed, it is also when the critics' creative work is highly affirmed. It begins with exploration and finally creates. The subject penetrates into the object and then transcends the object to identify with the subject. This process is also the process of the critic's circular creation. With the participation of critics' aesthetic interpretations, the life of the work continues.

\section{THE CONCLUSION}

The theories of the critics of the Geneva School have their own characteristics. George Bly's desire for spiritual identity, Jean Starobinski's "gaze", Jean Luce's attention to form, etc., all show their uniqueness. Therefore, while studying the commonalities of these critics, we should also pay attention to their respective critical theories. This is also one of the characteristics of the Geneva School. The critical consciousness theory of the Geneva School occupies a very important position in the entire history of the development of Western aesthetic interpretation. Although it will inevitably be limited by the times and the critics' own vision, and there are some defects and deficiencies, but the theory's emphasis on pure consciousness has a significant fulfillment and promotion significance for the field of aesthetic interpretation at that time and later. The proposition of this theory and methodology raised the aesthetic interpretation of literary and artistic works to a philosophical level, and made the aesthetic interpretation surpass a new height, becoming a subject with a more historical weight. It can be said that the Geneva School provides an expansion of research thinking for the aesthetic interpretation of literary and artistic works. Its unique theoretical insights and multiple critical methods have made important contributions to literary criticism and even aesthetic criticism, and not only greatly enriched aesthetics. Discipline also has an important theoretical influence in the current aesthetic research of art.

\section{REFERENCES}

[1] Jiang Kongyang, Zhu Liyuan, editors. General History of Western Aesthetics [M]. Shanghai Literature and Art Publishing House, 1999.

[2] [England] Eagleton. "Western Literary Theory in the Twentieth Century" [M]. Translated by Wu Xiaoming. Published by Shaanxi Normal University, 1987.

[3]Hu Jingzhi and Zhang Shouying. "History of Western Twentieth Century Literary Theory" [M]. China Social Sciences Press, 1988.

[4]Guo Hongan. "From Reading to Criticism-A Preliminary Study on the Critical Methodology of the 'Geneva School’" [M]. The Commercial Press, 2007.

[5][France] Roger Fayol. "Criticism: Method and History" [M]. Baihua Literature and Art Publishing House, 1999.

[6]Su Hongbin. "Introduction to Phenomenological Aesthetics"[M]. The Commercial Press, 2005. 